\title{
Pilot Study: What Measures Predict First Time Pass Rate on the National Physical Therapy Examination?
}

Jamie Bayliss

Mount St. Joseph University, jamie.bayliss@msj.edu

Rosanne M. Thomas

Mount St. Joseph University, rosanne.thomas@msj.edu

Marsha Eifert-Mangine

Mount St. Joseph University, marsha.eifert-mangine@msj.edu

Follow this and additional works at: https://nsuworks.nova.edu/ijahsp

Part of the Physical Therapy Commons

\section{Recommended Citation}

Bayliss J, Thomas RM, Eifert-Mangine M. Pilot Study: What Measures Predict First Time Pass Rate on the National Physical Therapy Examination?. The Internet Journal of Allied Health Sciences and Practice. 2017 Jan 01;15(4), Article 1.

This Manuscript is brought to you for free and open access by the College of Health Care Sciences at NSUWorks. It has been accepted for inclusion in Internet Journal of Allied Health Sciences and Practice by an authorized editor of NSUWorks. For more information, please contact nsuworks@nova.edu. 


\title{
Pilot Study: What Measures Predict First Time Pass Rate on the National Physical Therapy Examination?
}

\begin{abstract}
Background: Research investigating predictors of success on licensure examination is useful for admission criteria as well as targeted intervention for identified at risk students in physical therapy programs. Predictors of success on the National Physical Therapy Examination (NPTE) have been explored but results are no longer current. This study assessed predictive variables including admission data, performance in identified key courses, and academic/clinical difficulty for Doctor of Physical Therapy (DPT) cohorts at Mount St Joseph University. Objective: Determine variables predicting success on the National Physical Therapy Examination. Design: A retrospective correlational study was done. Methods: Retrospective data of Mount St Joseph University Doctor of Physical Therapy cohorts that matriculated between 2006 and 2011 was collected and de-identified. Data variables included admissions data, identified key course grades, evidence of academic difficulties, seven performance indicators from the Clinical Performance Instrument (CPI) during the final internship, and professional Grade Point Average (pGPA). Descriptive statistics, correlational matrix, factor analysis, and multiple regression were used to analyze relationships between and among independent variables to the dependent variable of National Physical Therapy Examination success. Results: Factor analysis revealed four factor categories of independent variables: Clinical Performance Instrument criteria, Doctor of Physical Therapy Academic Performance, Admissions Requirements, and Academic/Clinical Difficulty. Multiple regression identified academic performance within the Doctor of Physical Therapy program (foundational course grades and Grade Point Average) and verbal/quantitative Graduate Examination Record (v/qGRE) scores to be the greatest predictor of first time and ultimate pass rate on the National Physical Therapy Examination. Conclusion: Predictors of success on the National Physical Therapy Examination are essential for DPT programs to consider when making policies regarding admissions, academic standards, and early testing of the National Physical Therapy Examination. Additionally this information can assist Doctor of Physical Therapy programs in identifying at risk students and aiding them in seeking support services to assist their success.
\end{abstract}

\section{Author Bio(s)}

Jamie Bayliss, PT, DHSc, is a Director of Clinical Education and Assistant Professor in the Physical Therapy program at Mount St. Joseph University in Cincinnati, $\mathrm{OH}$.

Rosanne M Thomas, PT, PhD, is a Program Chair and Associate Professor in the Physical Therapy program at Mount St. Joseph University in Cincinnati, $\mathrm{OH}$.

Marsha Eifert-Mangine, PT, EdD, ATC, is an Associate Professor in the Physical Therapy program at Mount St. Joseph University in Cincinnati, $\mathrm{OH}$.

\section{Acknowledgements}

We thank Kathy Kraemer, Class of 2016 Doctor of Physical Therapy Student, for her assistance with setting up a data file in SPSS and data entry of the full data set into SPSS. 


\title{
IJAHSP \\ The Internet Joumnal of Allied Health Sciences and Practice \\ Dedicated to allied health professional practice and education
}

Vol. 15 No. 4 ISSN 1540-580X

\section{Pilot Study: What Measures Predict First Time Pass Rate on the National Physical Therapy Examination?}

\author{
Jamie Bayliss, PT, DHSc \\ Rosanne M. Thomas, PT, PhD \\ Marsha Eifert-Mangine, PT, EdD, ATC \\ Mount St. Joseph University
}

United States

\begin{abstract}
Background: Research investigating predictors of success on licensure examination is useful for admission criteria as well as targeted intervention for identified at risk students in physical therapy programs. Predictors of success on the National Physical Therapy Examination (NPTE) have been explored, but results are no longer current. This study assessed predictive variables including admission data, performance in identified key courses, and academic/clinical difficulty for Doctor of Physical Therapy (DPT) cohorts at Mount St Joseph University. Purpose: The purpose of this study was to determine variables predicting success on the National Physical Therapy Examination. Design: A retrospective correlational study was done. Methods: Retrospective data of Mount St Joseph University Doctor of Physical Therapy cohorts that matriculated between 2006 and 2011 were collected and de-identified. Data variables included admissions data, identified key course grades, evidence of academic difficulties, seven performance indicators from the Clinical Performance Instrument (CPI) during the final internship, and professional grade point average (pGPA). Descriptive statistics, correlational matrix, factor analysis, and multiple regression were used to analyze relationships between and among independent variables to the dependent variable of National Physical Therapy Examination success. Results: Factor analysis revealed four factor categories of independent variables: Clinical Performance Instrument criteria, Doctor of Physical Therapy Academic Performance, Admissions Requirements, and Academic/Clinical Difficulty. Multiple regression identified academic performance within the Doctor of Physical Therapy program (foundational course grades and grade point average) and verbal/quantitative Graduate Examination Record (v/qGRE) scores to be the greatest predictor of first time and ultimate pass rate on the National Physical Therapy Examination. Conclusion: Predictors of success on the National Physical Therapy Examination are essential for DPT programs to consider when making policies regarding admissions, academic standards, and early testing of the National Physical Therapy Examination. Additionally this information can assist doctor of physical therapy programs in identifying at risk students and aiding them in seeking support services to assist their success.
\end{abstract}

\section{INTRODUCTION}

Success on licensure examination can be viewed as the ultimate curricular assessment for healthcare professional academic programs and has strict requirements by most accreditation agencies including the Commission on Accreditation in Physical Therapy Education. Research investigating predictors of success on licensure examination would be useful for admission criteria as well as targeted intervention for identified at-risk students. Predictors of success on the National Physical Therapy Examination (NPTE) have been explored. 1-8,10,11 However, the majority of this research nationwide was done prior to 2012 before programs were consistently at a Doctor of Physical Therapy (DPT) level. Despite their age, these earlier findings indicated several predictor variables that may be useful to identify in a DPT candidate. Criteria identified in studies by Riddle et al, Utzman et al, Hollman et al, Dockter, Kosmahl et al, and Luedtke-Hoffmann et al set the foundation for further investigation that will be relevant in current professional curricula. ${ }^{1-5,7.8} \mathrm{As}$ the profession has evolved, there is an increasing mandate placed on physical therapy programs to graduate entry-level clinicians who are autonomous practitioners with sound clinical judgement in their management of patients. As described by the Federation of State Boards of Physical Therapy (FSBPT), the purpose of the NPTE is to measure an examinee's knowledge of clinical concepts and principles necessary for the provision of effective and

(C) The Internet Journal of Allied Health Sciences and Practice, 2017 
safe patient care that is required of an entry-level physical therapist. ${ }^{9}$ Considering such a responsibility, academic programs should consider predictors that may assist in determining student readiness and success. Thus, assessment of predictive variables were performed including admission data, grades in identified key courses, and academic/clinical difficulty for DPT cohorts at Mount St Joseph University (MSJ) during the years 2009 through 2014. A thorough investigation has facilitated datadriven policy decision-making to maximize student success on the NPTE licensure exam.

\section{Literature Review}

The first-time pass rate on the NPTE is of great importance to physical therapy programs nationally and has significant ramifications for several stakeholders such as DPT students, programs, and consumers including prospective faculty and student applicants who may compare institutional pass rates to the national pass rate as a measure of the merit of the individual institution. One of the stakeholders impacted greatly by failure on the NPTE is obviously the DPT graduate. At the time of graduation, the average DPT student will have accrued $\$ 96,129$ in debt according to a survey published by the American Physical Therapy Association (APTA) in 2011.10 This figure today, six years later, is likely higher and tops $\$ 100,000$ in student loans. While a student may be successful in graduating from a DPT program, the right to practice within the profession is only obtained by success on the NPTE. The cost to apply for and take the NPTE, without consideration of state specific application requirements, is $\$ 400 \cdot{ }^{13} \mathrm{Additional}$ costs are incurred from the Prometric testing center as well as a state jurisprudence exam. ${ }^{13}$ In the state of Ohio, the total cost for an applicant to become licensed is $\$ 550$ (cost of licensure, Prometric test center costs, and jurisprudence exam). Therefore, there are considerable financial implications for a graduate who is not successful on the first attempt. Not only are there additional costs with applying for and taking the test again, students often have insufficient funds to begin loan repayment within a six month period following graduation since they are unable to work as a licensed physical therapist while awaiting a retest date.

Another consideration that may affect a student's success in passing the NPTE is the student's ability to make the independent decision to sit for the licensure exam early. When the FSBPT announced fixed date testing in 2011, state licensing authorities were given the responsibility to decide whether students in that state could sit for the exam prior to graduation. ${ }^{14}$ All 32 states that allow early NPTE testing have specific requirements for being granted such an opportunity. ${ }^{15}$ The majority of state boards require completion of all didactic coursework within an academic program and anticipated graduation as evidenced by a precertificate of education completion form..$^{13}$ Though many students find it appealing to take the NPTE early allowing them to gain rapid employment to offset debt, many do not consider the emotional, physical, and mental fatigue associated with preparing for the NPTE while completing final academic requirements and/or clinical internships. Policies regarding early NPTE test taking among eligible programs run the gamut from full endorsement without restriction at one end to prohibition of taking the NPTE prior to graduation despite their state's position. Because of such variability, data analysis of predictors of success is vital for DPT programs to make appropriate, equitable policies.

Physical therapy programs are also stakeholders that may be affected by low first time pass rate of their students. The accreditation standards set by the Commission on Accreditation in Physical Therapy Education (CAPTE) ${ }^{16}$ mandate that a program prepare students for success on the NPTE. In the event that a program's pass rate is not adequate, the program may be put on probationary status. Not only would a probationary status negatively impact qualified student applicant recruitment, it may affect the program's reputation in the community, and within the region, negatively impact faculty and student resources and the general outlook of the profession as a whole.

\section{Factors Related to Success on the NPTE}

Many reasons for academic difficulty among physical therapy students and student performance on the NPTE have been proposed. ${ }^{1-8,10,11}$ Factors considered have included demographic and quantitative admissions data, admissions variables, standardized testing, academic difficulty, cognitive and non-cognitive predictors, clinical performance, program level variables, and educational program characterisitcs. ${ }^{1-8,10,11,17-19}$ Several of the studies have found more than one factor to be a predictor of academic success and success on the national licensure exam. Therefore, while no one factor explains a high level of variance related to academic difficulty and NPTE outcomes, several authors have suggested the need to consider the effect that multiple variables may have on student outcomes. .-8, $10,11^{-1}$

Two related studies by Utzman et al in 2007 investigated predictors that affect the performance of master's and doctoral level physical therapy students on the NPTE.,2,3 The initial study specifically explored the influence of undergraduate grade point average (uGPA), verbal Graduate Record Examination (vGRE) score, and quantitative Graduate Record Examination (qGRE) score on the occurrence of academic difficulty within physical therapy programs nationwide. ., $^{2,3}$ Logistic regression indicated that the contribution of those three variables were predictors of academic difficulty when other variables including academic program, cohort, degree level, ethnicity, and age were controlled. ${ }^{3}$ Utzman's later study used logistic regression analysis to identify uGPA,

(c) The Internet Journal of Allied Health Sciences and Practice, 2017 
VGRE, and qGRE as independent predictors for identifying individuals who were not successful on the first attempt of the NPTE. ${ }^{2}$ When analyzed further, the most consistent variable that predicted lack of first time success was vGRE score, which tests an individual's ability to analyze, evaluate, and synthesize relationships and concepts. ${ }^{2}$

Other authors have indicated academic difficulty while in a DPT program, defined by Riddle et al as "failing a course or unit or

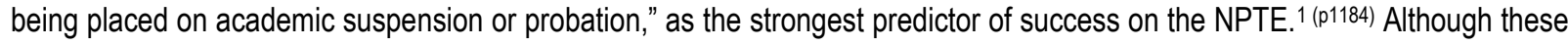
results have provided guidelines by which success on the NPTE may be predicted, the authors did not investigate the possibility of pGPA or specific academic coursework as predictors. Subjects in prior studies by Utzman et al and Riddle et al included masters, transitional doctorate, and doctor of physical therapy graduate students; however, all US physical therapy programs have now transitioned to the DPT degree. 1-3 $^{-3}$ The use of data from mixed entry-level programs are problematic when applying those outcomes to today's programs which are uniformly at the DPT level

Although the studies by Utzman et al did not investigate DPT program variables, Riddle et al examined the predictability of student failure on the NPTE based on student academic difficulty and program-level variables including private versus public institutional status and Carnegie Classification for students enrolled in masters, doctoral level, and transitional programs. ${ }^{1-3}$ Using a linear fixed-methods model, failure on the national exam was found to be 5.89 times higher for students who had academic difficulty in the physical therapy program compared to those who had not. ${ }^{1}$ Institutional status and Carnegie Classification, however, were not statistically significant predictors. ${ }^{1}$ Validating such findings today would allow physical therapy programs to ensure student readiness to take the NPTE licensure exam and to guide students in their decision to take the exam early or after graduation. The current study builds upon the findings of Riddle et al on academic difficulty by further defining types of academic difficulty and investigating how such academic performance may affect success on the NPTE.

Additional admission variables and their effect on NPTE outcomes have been explored. ${ }^{4,5}$ These included attainment of a baccalaureate degree, admission core course and science GPA, admission score, the number of admission clinical hours, interview score, and writing sample. ${ }^{4,5}$ While Hollman et al found conflicting evidence of specific measures that could predict post-graduation outcomes, Dockter observed the best predictor of performance on the NPTE to be pGPA at the end of the first year of a DPT program. ${ }^{4,5}$ Additional studies have investigated alternative variables such as program characteristics (cohort size, length of program in semesters and weeks, credit hours, etc.), student demographics (age, race, ethnicity), comprehensive exam, and clinical education (CE) variables (Clinical Performance Instrument ratings, percent of APTA credentialed clinical instructors, number of $C E$ credit hours, quantity of $C E$ affiliations, and length of $C E$ and terminal internships). $.7,8,10,11$ Kosmahl found that $47.7 \%$ of the variance for prediction of an NPTE score to be attributed to the two factors of pGPA and a cumulative comprehensive exam score. ${ }^{7}$ Conversely, Cook et al determined uGPA to have a significant association with programmatic three year pass rate, while age and UGPA have been associated with first time NPTE pass rate. ${ }^{11}$ Clinical performance and the variability within CE, however, were not found to predict performance on the NPTE by those authors who did include CE in their analysis. $7,8,11$ One theory regarding this finding is that clinical performance largely assesses psychomotor skills and clinical reasoning while the NPTE is a predominantly cognitive assessment.7,8,11

A more recent study by Fell et al investigated whether the preprofessional undergraduate degree is a significant predictor of student outcomes, academic program outcomes and success on the NPTE. ${ }^{20}$ This study included the following variables: undergraduate degree status, admission science GPA, cumulative GPA, professional GPA (pGPA), first attempt scale scores on the NPTE, and the number of attempts to pass the NPTE. ${ }^{20}$ Similar to Dockter and Kosmahl et al, admission science GPA and PGPA were predictors of first time pass rate on the NPTE. 5,7 Unlike previous studies, science GPA, PGPA, and degree status did predict the scale score of the first NPTE attempt. ${ }^{20}$ Fell et al, however, did not investigate the GRE as a variable despite previous reports in the literature indicating components of the GRE as predictors of success for national licensure exam pass rates. ${ }^{1-3,20}$

Because standardized tests have been addressed in the literature as having an association with academic performance and NPTE outcomes, it is appropriate to consider the validity of those most commonly reported in the literature. . $-3,6,10,17$ The GRE, developed in 1937 and most recently revised in 2011, has become a widely used entrance examination by many graduate programs including health professions graduate programs. ${ }^{17}$ The examination, composed of three sections, verbal reasoning (vGRE), quantitative reasoning (qGRE) and analytical writing (aGRE), has been shown to strongly correlate to success in graduate school, even though no section directly relates to a specific discipline. ${ }^{17}$ Predictive validity of the GRE on master and doctoral program GPAs has been widely studie, and the vGRE and qGRE are supported to be valid predictors of academic performance in graduate school in a recent meta-analysis of the available research. ${ }^{18}$ Low performance on the vGRE and qGRE combined with low uGPA appears to correlate with performance in physical therapy programs and/or on the NPTE, though there

() The Internet Journal of Allied Health Sciences and Practice, 2017 
is little evidence to support this. ${ }^{2,3}$ Investigation of the GRE in other health care disciplines indicated a positive predictive validity of cumulative GPA between UGPA and GRE scores in occupational therapy as well as physician assistant programs. ${ }^{17}$

\section{METHODS}

\section{Study Design}

A retrospective correlational study of matriculated students in the Doctor of Physical Therapy program at Mount St. Joseph University (MSJ) was conducted. The study took place from September 17, 2014, through September 17, 2015, and was approved by the Institutional Review Board at MSJ.

All data were collected from electronic records housed on the Department of Physical Therapy's network drives, the department's Clinical Education network drive, admissions database, student academic files, the American Physical Therapy Association's (APTA) CPI Web online portal, and the Physical Therapy Centralized Application Service (PTCAS) website. Data was deidentified and stored on the primary investigators' secure personal network drives through the institution for the duration of the study.

\section{Data Set}

The data set was identified through student departmental databases and represent students enrolled in MSJ's Doctor of Physical Therapy Program. Inclusion criterion for participants was matriculation into the DPT Program at MSJ between 2006 and 2011. The data set included data from 175 student records.

\section{Data}

The data variables examined included undergraduate institution and degree, admissions data, grades in identified key program courses, evidence of academic/clinical difficulties, the Clinical Performance Instrument (CPI) during the final clinical internship, and pGPA. Seven performance indicators from the final assessment of the final clinical internship CPI were included despite findings from Luedtke-Hoffmann et al that only small correlations existed between the Physical Therapist Manual for the Assessment of Clinical Skills (PT MAC) and NPTE scores. ${ }^{13}$ Admissions data included Graduate Record Examination (GRE) scores at time of matriculation into the program (quantitative, verbal, analytical), undergraduate grade point average (uGPA), and undergraduate science GPA (usciGPA).

Academic difficulties as defined by the program include Warning (a semester <3.0/4.0 GPA but a cumulative GPA >3.0/4.0), Probation (a cumulative GPA <3.0/4.0 for one semester), and Dismissal, often as a result of failing a course, with reinstatement, following a successful student appeal process. Individual student grades in first year key courses included BIO 526 - Gross Anatomy, PT 601 - Foundational Science I, PT 608 - Biomechanics/Kinesiology, PT 624 -- Neuroscience, while individual student grades in second year key courses included PT 715 - Acute Care and Cardiopulmonary, and PT 720 - Orthopedics I. Course descriptions of targeted courses are included in Table 1 to acknowledge the uniqueness of DPT programs' curricular models while allowing for the reader to seek commonality among programs. Though course titles may vary, content may be similar across programs because of accreditation requirements. The first year courses were chosen as they are representative of the foundational coursework that is embedded throughout the rest of the curriculum. The second year courses that were included are patient management courses that include labs and have higher credit hour value. Additionally, the key courses included in the study were chosen based on the history of student pGPAs and were the courses in which students most frequently had poor grades. Cohort data were collected in the aggregate for gender, age, and number of students who graduated to define demographics.

\section{Statistical Analysis}

Descriptive statistics, correlational statistics, factor analysis, and multiple regression were analyzed for the full data set using IBM SPSS Statistics for Windows, Version 22.0 (IBM Corp., Armonk, NY). Descriptive statistics were used to analyze the demographic data. Nominal data was presented as frequencies and percentages, ordinal data as medians and $25^{\text {th }}$ and $75^{\text {th }}$ percentiles, and continuous data as means and standard deviations. A one-way ANOVA was run to compare the various GPAs between the cohorts. Pearson's product moment correlation coefficient was utilized to assess correlational statistics between independent variables. A factor analysis was run to collapse the variables into a manageable number and for ease of interpretation since analysis of factors as opposed to a significant number of independent variables would serve as a more comprehensive way to identify global factors that may predict success on the NPTE. The initial factor analysis reduced the variables into eight factors. Following interpretation of the eight factors, a principle component factor analysis with varimax rotation was run with a fixed number of four factors for extraction. A varimax rotation is used when we assume that not all factors

() The Internet Journal of Allied Health Sciences and Practice, 2017 
in the analysis are correlated whereas oblique rotation methods assume that each factor is correlated. Not all of the independent variables were found to correlate to one another; therefore, a varimax rotation was used for the analysis. A multiple regression was run to determine the extent to which a relationship exists between first-time and ultimate NPTE pass rate and the four factors. Independent $t$-tests were run to determine if there were differences in GRE scores between students who were successful and those who weren't successful on the NPTE based on previous findings identified in the literature..$^{1-3}$ All comparisons were two-tailed and significance level of .05 was considered statistically significant.

\section{RESULTS}

\section{Descriptives}

Data on 175 DPT student records were included in the study. Descriptives for the study's student pool can be found in Table 2. The median age of the students at the time of matriculation into the MSJ DPT program was 26.5 years. The student pool was comprised of $72 \%$ females and $28 \%$ males. The aggregate admission uGPA scores across all cohorts ranged from 3.27 to 3.81 while the usciGPA ranged from 3.02 to 3.07. Programmatic GPA for the cohorts upon graduation ranged from 3.45 to 3.69 .

\section{Comparison of the Cohorts}

A one-way ANOVA revealed no statistically significant difference within or between cohorts for the $\operatorname{pGPA}(F(6,156)=12.739, p$ $=.096)$, uGPA $(F(6,156)=.394, p=.855)$ and usciGPA $(F(6,156)=.327, p=.967)$.

\section{Correlation between Independent and Dependent Variables}

A Pearson correlation matrix illustrated positive correlations between several independent variables and first-time pass rates on the NPTE: v/qGRE, pGPA, Bio 526 - Gross Anatomy, PT 601 - Foundational Science I, PT 608 - Biomechanics/Kinesiology, PT 624 - Neuroscience and PT 715 - Acute Care and Cardiopulmonary (Table 3). The most significant correlations were found between first-time pass rate and $\mathrm{pGPA}$.

\section{Factor Analysis}

A factor analysis was used to reduce the dimensions of observations by grouping similar variables, thereby reducing the number of variables for further statistical analysis. Considering the number of independent variables initially incorporated in the data set, a factor analysis was run to condense the number of variables for analysis. The principle component factor analysis included a varimax rotation, which reduces the occurrence of multi-collinearity within the independent variables and simplifies the interpretation of the factors. ${ }^{23}$ Results from the principle component factor analysis with varimax rotation can be found in Tables 4 and 5 .

\section{Regression}

A multiple regression was used to determine if one or more independent variables could predict the value or outcome of firsttime and ultimate NPTE pass rate. A multiple regression was performed using 1) the four factors and specific independent variables that were statistically significant following the factor analysis for first time pass rate and 2) the four factors and specific independent variables that were statistically significant following the factor analysis for ultimate pass rate. The choice to use a multiple regression was based on its appropriateness with dichotomous or continuous variables. ${ }^{23}$ Results of the multiple regressions are represented in Table 6.

Multiple regression of the four factors indicated Factor 2: Academic Performance within the DPT program to be the greatest predictor of first time (A) (Factor $1-p>.05$, Factor $2-p<.001$, Factor $3 p>.05$, and Factor $4 p>.05$ ) and ultimate pass rate (B) (Factor $1-p>.05$, Factor $2-p<.001$, Factor $3 p>.05$, and Factor $4 p>.05$ ) on the NPTE.

\section{Comparison of Success Related to GRE}

Utzman et al and Riddle et al previously reported v/qGRE to be a predictor of success on the NPTE. Independent $t$-tests were run based on previous reports in the literature and the strong correlation between v/q GRE and NPTE outcomes in this study. A statistically significant difference in NPTE outcomes is noted based on v/q GRE $(p=.002) 1^{1-3}$

\section{DISCUSSION}

Predictors of success on the NPTE are essential for DPT programs to consider when selecting and advising students. The results of the present study support previous findings that academic performance (or difficulty therein) and admission data predict student performance on the NPTE. ${ }^{1-3}$ This study further investigates academic scores in greater depth than any previous study based on observations that students tend to have academic difficulty in specific coursework while progressing through the DPT

(C) The Internet Journal of Allied Health Sciences and Practice, 2017 
program at MSJ. As mentioned previously, Factor 2 - DPT academic scores had the strongest correlation with regard to outcomes on the NPTE. Multiple regression analysis, investigating the relationship between NPTE pass rate and factor variables, provided further, more comprehensive interpretation of which factors ultimately influence performance on the NPTE. The single most influential variable was the Factor 2- DPT academic component (Table 5). Thus, as the Factor 2 - DPT academic scores increased (regression model outcome for the combined pGPA, BIO 526 - Gross Anatomy, PT 601 - Foundations I, PT 624 Neuroscience, PT 608 - Biomechanics/Kinesiology, PT 715 - Acute Care and Cardiopulmonary , and PT 720 - Orthopedics I variables), there was a greater likelihood of students being successful on the NPTE.

The presence of a significant relationship between v/qGRE, academic performance, and success on the NPTE indicates that perhaps the outcome on the NPTE is multifactorial. Previous findings by Dockter, Kosmahl et al, and Utzman et al, found an association between multiple factors and the success of students on the NPTE, though none of the factors investigated in previous studies investigated beyond program GPA.,2,3,5 An examination of specific clinical content within courses is unique to the current study and is a factor likely to contribute to success on the NPTE.

The results of this study importantly show that analysis and findings exclusively at the DPT level support the previous work by Utzman et al, Riddle et al, Dockter, Kosmahl, and Fell et al done at the MPT and DPT levels. . $^{1-3,5,7,20}$ Despite the variability in curricular model of each physical therapy program, programs can use content similarities to the present study to suggest areas for analysis within individual programs to determine predictor(s) unique to their program in an effort to improve student outcomes. Additionally, this study's results provide statistical evidence that programmatic grades and pGPA within a DPT program can assist faculty in predicting a student's success on the NPTE. These findings have already driven change in the MSJ DPT program and have guided admission policy and weight of the GRE. The results of this study, indicating predictors of success as course grades, pGPA, and v/qGRE, have assisted the program's faculty in determining students' readiness to take the exam and counseling students who desire to take the NPTE early. These predictors also guide faculty in determining whether or not a student may require proactive remediation within the didactic portion of the curriculum. Finally, they are used to guide further policy development for a DPT program allowing early test taking of the NPTE.

\section{LIMITATIONS}

Generalizability of the data from one institution's DPT program should be considered with caution. While each physical therapy program is unique, the student demographics at MSJ are congruent with the national physical therapy student profile. ${ }^{21}$ Additionally, the findings previously reported by Utzman et al and Riddle et al do coincide with the findings of this study; therefore, consideration of the results from this study add to the body of research investigating factors contributing to success on the NPTE and additionally investigate specific coursework that may correlate with NPTE outcome. ${ }^{1-3}$

Prior to the class of 2017 that matriculated in 2014, undergraduate students of MSJ's institution were not required to take the GRE. The MSJ undergraduate students in the study account for $18.6 \%$ of the data set, therefore reducing the number of GRE data points. The missing data was addressed by coding the data as missing instead of replacing the missing data points using another method such as averaging the data from each respective cohort's GRE scores.

Two additional nuances that need to be considered as possible limitations are the fluidity of a DPT curriculum between cohorts and the uneven cohort size. As with any academic program, curricular changes with regard to course content, course instructors, or course placement within a curriculum may impact student outcomes. There were curricular changes since the inception of the DPT program in 2006 including change to course content and the variability of course instructors who taught the foundational courses included in the study. The greatest curricular change was moving from integrated full-time clinical experiences to terminal clinical internships. Despite the evolution of the program and curriculum over time, credence should be given to the fact that such changes are typical of a dynamic physical therapy curriculum.

Change in the NPTE procedures to fixed date testing should also be considered. Fixed date testing was implemented in July of 2011. Prior to 2011, physical therapy students could register for and take the NPTE at any time. One of the greatest implications on fixed date testing is the strain it may place on students financially should they have to wait after graduation to take the test. Alternatively, the increased pressure of studying for and passing the exam concurrent with clinical internships or end of curriculum didactic coursework poses additional concerns about a student's ability to be successful.

Finally, the multiple regression analysis using a dichotomous dependent variable is not as robust as using a continuous dependent variable. The decision to dichotomize the dependent variable was based on the limited available NPTE scores for

() The Internet Journal of Allied Health Sciences and Practice, 2017 
the sample. If the actual NPTE scores had been used instead of "pass/fail," nearly a third of the data would not have been available, thereby reducing the sample size and threatening the internal validity.

\section{FUTURE DIRECTIONS}

Future consideration for further investigation includes validation of the GRE's predictive validity as an admission criteria for PT programs because this study indicates that GRE scores positively correlate with NPTE success This could influence recent proposals by the American Council of Academic Physical Therapy (ACAPT) to develop a Physical Therapist Education-Specific Admissions Examination. ${ }^{22}$ Additional variables could also be considered including completion of the program within one's matriculated cohort as compared to students who may have a delayed graduation. Continued collection of data through the program's current cohorts should also be considered as it would increase the $N$ and improve power of the study. Investigation into classroom curricular design and clinical education curricular model may also enhance the understanding of what variables may impact student outcomes on the NPTE. Lastly, future endeavors will include collaboration with regional and national programs on the predictors of success on the NPTE.

\section{CONCLUSION}

This pilot study examined the predictors of first-time and ultimate pass rate on the NPTE. A secondary intent of the study was to guide policy development and the means to determine at-risk students who may require remediation for a DPT program in a state that allows early test taking of the NPTE. Predictors of success on the NPTE are essential for DPT programs to consider when selecting and advising students. Results indicate that Factor 2 - DPT Academic Scores (pGPA, BIO 526 - Gross Anatomy, PT 601 - Foundations I, PT 624 - Neuroscience, PT 608 - Biomechanics/Kinesiology, PT 715 - Acute Care and Cardiopulmonary , and PT 720 - Orthopedics I variables) and v/q GRE are predictors of first-time and ultimate pass rate on the NPTE. These findings go beyond those of Utzman et al and Riddle et al in acknowledging the significance that variables other than GRE and undergraduate measures may have on licensure pass rate..$^{1-3}$ The results of this and future studies will be referenced when making future policies within the MSJ DPT program, in guiding students who require remedial coursework, as well as enhancing matriculated students' success in becoming licensed physical therapists by assessing and validating the need for additional resources.

\section{References}

1. Riddle $D$, Utzman $R$, Jewell $D$, Pearson $S$, Kong $X$. Academic difficulties and program-level variables predict performance on the National Physical Therapy Examination for Licensure: A population-based cohort study. Phys Ther. 2009; 89:118291. [PMID: 19762483]

2. Utzman R, Riddle D, Jewell D. Use of demographic and quantitative admissions data to predict performance on the National Physical Therapy Examination. Phys Ther. 2007; 87:1181-93. [PMID: 17609335]

3. Utzman R, Riddle D, Jewell D. Use of demographic and quantitative admissions data to predict academic difficulty among professional physical therapy students. Phys Ther. 2007; 87:1164-80. [PMID: 17609336]

4. Hollman J, Rindflesch A, Youdas J, Krause D, Hellyer N, Kinlaw D. Retrospective analysis of the behavioral interview and other admission variables to predict licensure examination outcomes in physical therapy. J Allied Health. 2008;37:97-104. [PMID: 18630785]

5. Dockter M. An analysis of physical therapy admission factors on academic success and success on the national licensing examination. J Phys Ther Educ. 2001;15(1):60-4.

6. Galleher C, Rundquist P, Barker D, Chang W. Determining cognitive and non-cognitive predictors of success on the National Physical Therapy Examination. Internet J Allied Health Sciences and Prac. http://ijahsp.nova.edu. 2012, 10:4 ISSN 1540-580X.

7. Kosmahl E. Factors related to physical therapist license examination scores. J Phys Ther Educ. 2005;19(2):52-6.

8. Luedtke-Hoffmann K, Dillon L, Utsey C, Tomaka J. Is there a relationship between performance during physical therapist clinical education and scores on the National Physical Therapy Examination (NPTE)? J Phys Ther Educ. 2012;26(2):41-9.

9. Federation State Boards of Physical Therapy. PT Content Outline. Available at https://www.fsbpt.org/downloads/FreeResources/PTContentOutline.aspx. Accessed July 8, 2017.

10. Mohr T, Ingram D, Hayes S, Du Z. Educational program characteristics and pass rates on the National Physical Therapy Examination. J Phys Ther Educ. 2005;19(1):60-6.

11. Cook C, Engelhard C, Landry M, McCallum C. Modifiable variables in physical therapy education programs associated with first-time and three-year National Physical Therapy Examination pass rates in the United States. J Educ Eval Health Prof. 2015;12:44. http://dx.doi.org/10.3352/jeehp.2015.12.44.

() The Internet Journal of Allied Health Sciences and Practice, 2017 
12. American Physical Therapy Association. Legislation to Increase Access to Physical Therapy Services for Patients in Underserved Communities. Available at http://www.apta.org/Media/Releases/Legislative/2011/4/8/. Published April 8, 2011. Accessed July 8, 2017.

13. Federation State Boards of Physical Therapy. Exam Registration \& Payment. Available at https://www.fsbpt.org/ourservices/candidateservices/examregistrationpayment.aspx. Accessed July 8, 2017.

14. ADVANCE Perspective: Physical Therapy and Rehab Medicine. Cheating Scandals Change PT Certification Exams. Available at http://community.advanceweb.com/blogs/pt_1/archive/2011/03/30/cheating-scandals-change-pt-certificationexams.aspx. Published March 30, 2011. Accessed July 8, 2017.

15. Federation State Boards of Physical Therapy. Jurisdiction Licensure Reference Guide Topic: Taking the NPTE before Graduation. Available at https://www.fsbpt.org/download/JLRG_TakingNPTEPriorToGrad_201507.pdf. Accessed August 8, 2016.

16. Commission on Accreditation in Physical Therapy Programs. CAPTE Accreditation Handbook. Available at http://www.capteonline.org/AccreditationHandbook/. Updated July 15, 2016. Accessed July 8, 2017.

17. Hocking J, Piepenborck K. Predictive ability of the Graduate Record Examination and its usage across physician assistant programs. J Physician Assist Educ. 2010;21:18-22. [PMID: 21366111]

18. Kuncel N, Wee S, Serafin L, Hezlett S. The validity of the graduate record examination for master's and doctoral programs: a meta-analytic investigation. Educational and Psychological Measurement. 2010;70:340-52. DOI: 10.1177/0013164409344508

19. Roach K, Frost J, Francis N, Giles S, Nordrum J, Delitto A. Validation of the revised physical therapist Clinical Performance Instrument (PT CPI): Version 2006. Phys Ther. 2012;92(3):416-28. [PMID: 22135710]

20. Fell N, Mabey R, Mohr T, Ingram D. The preprofessional degree: is it a predictor of success in physical therapy education programs? J Phys Ther Educ. 2015;29(3):13-21.

21. Aggregate program data: 2014-2015 physical therapist education programs fact sheets. Commission on Accreditation of Physical Therapy Education Website. http://www.capteonline.org/uploadedFiles/CAPTEorg/About_CAPTE/Resources/Aggregate_Program_Data/AggregatePro gramData_PTPrograms.pdf. Updated August 10, 2015. Accessed September 28, 2015.

22. American Council of Academic Physical Therapy. Physical Therapist Education-Specific Admissions Examination. Available at http://www.acapt.org/news/news-detail/2016/09/30/physical-therapist-education-specific-admissionsexamination-questionnaire---respond-by-september-30. Published September 30, 2016. Accessed October 7, 2016.

23. Hair J, Anderson R, Tatham R, Black W. Multivariate Data Analysis, 5e. Upper Saddle River, NJ: Prentice-Hall; 1984. 
Table 1. Mount St. Joseph University Doctor of Physical Therapy Identified Key Course Descriptions ${ }^{\text {a }}$

\begin{tabular}{|c|c|c|}
\hline Course Names & Course Descriptions & $\begin{array}{l}\text { Course } \\
\text { Credit hours }\end{array}$ \\
\hline BIO 526 - Gross Anatomy & $\begin{array}{l}\text { Complete study of the anatomy of the human body that } \\
\text { places emphasis on the relationships of the skeletal, } \\
\text { muscular, and peripheral vascular and nervous systems. }\end{array}$ & 8 \\
\hline $\begin{array}{l}\text { PT } 601 \text { - Foundational } \\
\text { Science I }\end{array}$ & $\begin{array}{l}\text { First course in a series of basic science courses where } \\
\text { students review the etiology, pathogenesis, clinical } \\
\text { manifestations and medical management for selected } \\
\text { pathologies. Additional emphasis is placed on the impact of } \\
\text { pharmacology and medical imaging on physical therapy } \\
\text { management. }\end{array}$ & 4 \\
\hline $\begin{array}{l}\text { PT } 608 \text { - } \\
\text { Biomechanics/Kinesiology } \\
\text { w/ Lab }\end{array}$ & $\begin{array}{l}\text { Study of the principles of musculoskeletal biomechanics } \\
\text { and kinesiology including mechanical behavior and } \\
\text { properties of bone, tendon, ligament, joint, cartilage, and } \\
\text { skeletal muscle as applied to the human body. }\end{array}$ & 4 \\
\hline PT 624 - Neuroscience & $\begin{array}{l}\text { Course reviewing the functional anatomy and physiology of } \\
\text { the human nervous system. Gross anatomical structures and } \\
\text { their function, including motor and sensory systems as well } \\
\text { as higher cognitive regions, are discussed and correlated } \\
\text { with clinical neurologic dysfunction. }\end{array}$ & 3 \\
\hline $\begin{array}{l}\text { PT } 715 \text { - Acute Care and } \\
\text { Cardiopulmonary w/ Lab }\end{array}$ & $\begin{array}{l}\text { Examination, evaluation, treatment interventions, and } \\
\text { discharge planning for patients treated in the acute care } \\
\text { setting, including the intensive care unit. Emphasis is placed } \\
\text { upon synthesis, analysis, and integration of subjective and } \\
\text { objective patient data for evidence based clinical decision } \\
\text { making. }\end{array}$ & 3 \\
\hline $\begin{array}{l}\text { PT } 720 \text { - Orthopedics I w/ } \\
\text { Lab }\end{array}$ & $\begin{array}{l}\text { A regional approach to examination, evaluation, treatment } \\
\text { planning, therapeutic exercise, and manual therapy } \\
\text { intervention techniques for common musculoskeletal } \\
\text { conditions of the cervical spine, TMJ, thoracic spine and the } \\
\text { upper extremities is studied. }\end{array}$ & 6 \\
\hline
\end{tabular}

a Course description data collected from Mount St. Joseph University AKA

College of Mount St. Joseph Doctor of Physical Therapy graduate course catalog 
Table 2. Mount St. Joseph University Doctor of Physical Therapy Program Participant Descriptives by Cohort

\begin{tabular}{|c|c|c|c|c|c|c|c|c|c|c|}
\hline Cohort & Gender & $\begin{array}{l}\text { Total \# of } \\
\text { Students }\end{array}$ & $\begin{array}{c}\text { \# of } \\
\text { Students } \\
\text { Graduated }\end{array}$ & $\begin{array}{c}>36 \text { Months } \\
\text { to Graduate } \\
\text { (Moved to } \\
\text { Next } \\
\text { Cohort) }\end{array}$ & $\begin{array}{c}\text { \# of } \\
\text { Students } \\
\text { Not } \\
\text { Graduated }\end{array}$ & $\begin{array}{c}\text { Age } \\
\text { Range } \\
\text { (years } \\
\text { old) }\end{array}$ & $\begin{array}{c}\text { Average } \\
\text { Age }\end{array}$ & $\begin{array}{c}\text { Aggregate } \\
\text { uGPA }^{\mathrm{a}}\end{array}$ & $\begin{array}{l}\text { Aggregate } \\
\text { uSciGPA }^{\text {b }}\end{array}$ & pGPA $^{c}$ \\
\hline 2009 & $\begin{array}{l}M=3 \\
F=13\end{array}$ & 16 & 14 & - & 2 & $23-30$ & 27 & 3.27 & 3.07 & 3.47 \\
\hline 2010 & $\begin{array}{l}M=3 \\
F=18\end{array}$ & 21 & 19 & - & 2 & $25-29$ & 26 & 3.67 & 3.07 & 3.55 \\
\hline 2011 & $\begin{array}{l}M=9 \\
F=20\end{array}$ & 29 & 27 & - & 2 & $24-46$ & 27 & 3.81 & 3.05 & 3.67 \\
\hline 2012 & $\begin{array}{l}M=9 \\
F=27\end{array}$ & 36 & 32 & 1 & 3 & $25-29$ & 26 & 3.38 & 3.05 & 3.67 \\
\hline 2013 & $\begin{array}{l}M=7 \\
F=26\end{array}$ & 33 & 24 & 3 & 6 & $25-39$ & 27 & 3.33 & 3.03 & 3.69 \\
\hline 2014 & $\begin{array}{l}M=18 \\
F=22\end{array}$ & 40 & 40 & - & - & $25-30$ & 26 & 3.35 & 3.02 & 3.45 \\
\hline $\begin{array}{l}\text { Aggregate } \\
\text { Data }\end{array}$ & $\begin{array}{l}M=49 \\
F=126\end{array}$ & 175 & 156 & 4 & 15 & $23-46$ & 26.5 & 3.47 & 3.05 & 3.58 \\
\hline
\end{tabular}

auGPA = undergraduate grade point average

buSciGPA = undergraduate science grade point average

cpGPA = professional grade point average

Table 3. Pearson Correlations Independent Variables - First Time Pass Rate NPTE

\begin{tabular}{|c|c|c|}
\hline Independent Variablea & Correlation Coefficient & Significance Level $^{\mathbf{b}}$ \\
\hline v/qGRE & $r=.291$ & $p<.002$ \\
Bio 526 & $r=.296$ & $p<.001$ \\
PT 601 & $r=.202$ & $p<.011$ \\
PT 608 & $r=.256$ & $p<.001$ \\
PT 624 & $r=.231$ & $p<.004$ \\
pGPA & $r=.315$ & $p<.001$ \\
AD (Warning) & $r=-.296$ & $p<.001$ \\
AD (Dismissal) & $r=-.327$ & $p<.001$ \\
\hline
\end{tabular}

a v/qGRE = verbal/quantitative Graduate Record Examination, Bio 526 = Gross Anatomy, PT 601 = Foundational Science I, PT $608=$ Biomechanics $/$ Kinesiology, PT $624=$ Neuroscience,$A D=$ Academic difficulty

${ }^{\mathrm{b}}$ Pearson correlation coefficient $=-1$ (negative association), 0 (no association), +1 (strong association)

cSignificance level $p<.05$ 
Table 4. Factor Analysis Factor Components

\begin{tabular}{|c|c|c|c|}
\hline $\begin{array}{c}\text { Factor 1 } \\
\text { CPI Performance Criteriaa }\end{array}$ & $\begin{array}{c}\text { Factor 2 } \\
\text { DPT Academics }\end{array}$ & $\begin{array}{c}\text { Factor 3 } \\
\text { Admissions Datac }\end{array}$ & $\begin{array}{c}\text { Factor 4 } \\
\text { Academic/Clinical Difficulty }\end{array}$ \\
\hline CPI \# 7 & pGPA & Total Admissions Points & Evidence of Academic Warning \\
CPI \# 8 & BIO 526 & UGPA & (One semester <3.0 GPA) \\
CPI \# 9 & PT 601 & USci GPA & GRence of Academic Probation \\
CPI \# 10 & PT 624 & GRE V/Q & (One semester cumulative GPA $<3.0)$ \\
CPI \# 11 & PT 608 & Chem GPA & Evidence of Academic Difficulties \\
CPI \# 12 & PT 715 & Physics GPA & (Dismissal) \\
CPI \# 13 & PT 720 & A \& P GPA & Evidence of Clinical Education Difficulties \\
& & & (Clinical Remediation) \\
& & & \\
\hline
\end{tabular}

a, $\mathrm{CPI}=$ Clinical Performance Instrument

${ }^{\mathrm{b}}$ Bio 526 = Gross Anatomy, PT $601=$ Foundational Science I, PT $608=$ Biomechanics $/$ Kinesiology, PT $624=$

Neuroscience, PT $715=$ Acute Care and Cardiopulmonary, PT $720=$ Orthopedics I

${ }^{\circ}$ uGPA = undergraduate Grade Point Average, usciGPA = undergraduate science Grade Point Average, v/qGRE =

verbal/quantitative Graduate Record Examination, Chem = chemistry, A \& P = anatomy and physiology

Table 5. Rotated Component Matrix

\begin{tabular}{|c|c|c|c|c|}
\hline & Component & & & \\
\hline Variable & $\begin{array}{c}1 \text { CPI Performance } \\
\text { Criteria }\end{array}$ & $\underline{2}$ DPT Academics & 3 Admissions Data & $\begin{array}{l}\text { 4 Academic/Clinical } \\
\text { Difficulty }\end{array}$ \\
\hline Total admission points & & & .888 & \\
\hline $\begin{array}{l}\text { Total admission points } \\
\text { percentage }\end{array}$ & & & .889 & \\
\hline Interview raw score & & & .493 & \\
\hline GPA overalla & & & .442 & \\
\hline GPA science & & & .467 & \\
\hline GRE $v / q^{b}$ & & & .522 & \\
\hline GRE analytical & & & .191 & \\
\hline$A \& P G P A^{c}$ & & & .340 & \\
\hline $\begin{array}{l}\text { Evidence of Academic } \\
\text { Difficulties (warning) }\end{array}$ & & & & .462 \\
\hline $\begin{array}{l}\text { Evidence of Academic } \\
\text { Difficulties (probation) }\end{array}$ & & & & .470 \\
\hline $\begin{array}{l}\text { Evidence of Academic } \\
\text { Difficulties (dismissal) }\end{array}$ & & & & .749 \\
\hline $\begin{array}{l}\text { Evidence of Clinical Education } \\
\text { Difficulties }\end{array}$ & & & & .444 \\
\hline Final cumulative GPA & & .792 & & \\
\hline Bio $526^{d}$ & & .588 & & \\
\hline PT $601^{\mathrm{e}}$ & & .700 & & \\
\hline PT $608^{f}$ & & .523 & & \\
\hline PT 6249 & & .498 & & \\
\hline PT 720h & & .325 & & \\
\hline PT 715 & & .528 & & \\
\hline CPI PI \#7 & .926 & & & \\
\hline CPI PI \#8 & .826 & & & \\
\hline CPI PI \#9 & .858 & & & \\
\hline CPI PI \#10 & .796 & & & \\
\hline CPI PI \#11 & .792 & & & \\
\hline CPI PI \#12 & .889 & & & \\
\hline CPI PI \#13 & .809 & & & \\
\hline
\end{tabular}


Table 6. Multiple Regression Analysis

\begin{tabular}{|c|c|c|c|}
\hline & Regression Equation & $\mathbf{R}^{2}$ & $\begin{array}{c}\text { Standard } \\
\text { Error of } \\
\text { the } \\
\text { Estimate }\end{array}$ \\
\hline $\begin{array}{l}\text { A. First Time Pass Rate in Relation to Four } \\
\text { Factors }\end{array}$ & $\begin{array}{c}\mathrm{F}(4,105)=5.464, p<.001 \\
\text { Factor } 1^{\mathrm{a}}-p=.343 \\
\text { Factor } 2^{\mathrm{b}}-p<.001 \\
\text { Factor } 3^{\mathrm{c}}-p=.608 \\
\text { Factor } 4^{\mathrm{d}}-p=.091\end{array}$ & .172 & .344 \\
\hline $\begin{array}{l}\text { B. Ultimate Pass Rate in Relation to Four } \\
\text { Factors }\end{array}$ & $\begin{array}{c}\mathrm{F}(1,108)=17.959, p<.001 \\
\text { Factor } 1-p=.446 \\
\text { Factor } 2=p<.001 \\
\text { Factor } 3-p=.611 \\
\text { Factor } 4-p=.109\end{array}$ & .143 & .346 \\
\hline
\end{tabular}

a Factor 1 - Clinical Performance Instrument

b Factor 2 - DPT academics

c Factor 3 - Admissions data

d Factor 4 - Academic/clinical difficulty 